\title{
Use of antidepressants and mood stabilizers in persons with first-episode schizophrenia
}

\author{
Arto Puranen $^{1,2}$ (D) M Marjaana Koponen ${ }^{2,3}$ (D) - Antti Tanskanen ${ }^{1,4}$ (D) Jari Tiihonen ${ }^{1,4,5}$ (D) Heidi Taipale ${ }^{1,2,4}$ (D)
}

Received: 8 August 2019 / Accepted: 6 January 2020 / Published online: 15 January 2020

(C) The Author(s) 2020

\begin{abstract}
Purpose Antipsychotics are first-line treatment of schizophrenia. They are often accompanied by adjunctive treatments, such as antidepressant (AD) or mood stabilizer (MS), although there is only limited information of their use in first-episode schizophrenia. This study aimed to investigate AD and MS initiation and factors associated with initiation in persons with first-episode schizophrenia.

Methods Register-based data was utilized to identify persons who received inpatient care due to schizophrenia during 19962014 in Finland and who did not use AD or MS at the time of first inpatient care diagnosis of schizophrenia $(N=7667$, mean age 40.2, SD 18.2). Drug purchase data (1995-2017) was obtained from the National Prescription register and modelled with PRE2DUP method. Initiations of AD and MS use were followed up 3 years from first schizophrenia diagnoses. Cox proportional hazard models were used to investigate factors associated with AD or MS initiation.

Results Among persons with first-episode schizophrenia, 35.4\% initiated AD and 14.1\% initiated MS use within three years from diagnoses. Female gender, younger age, and benzodiazepine use were associated with higher risk of AD and MS initiation. The number of previous psychoses was associated with decreased risk of AD and increased risk of MS initiation.

Conclusion Clinical guidelines rarely recommend the use of AD or MS as adjunctive treatment in persons with schizophrenia. However, this population is often treated with AD or MS. More studies are needed to evaluate benefits and risks of these medications as adjunctive treatment of schizophrenia.
\end{abstract}

Keywords Antidepressants · Antipsychotics $\cdot$ Mood stabilizers $\cdot$ Schizophrenia

Electronic supplementary material The online version of this article (https://doi.org/10.1007/s00228-020-02830-2) contains supplementary material, which is available to authorized users.

Arto Puranen

avpurane@student.uef.fi

1 Department of Forensic Psychiatry, University of Eastern Finland, Niuvanniemi Hospital, Kuopio, Finland

2 School of Pharmacy, University of Eastern Finland, Kuopio, Finland

3 Centre for Medicine Use and Safety, Faculty of Pharmacy and Pharmaceutical Sciences, Monash University, Parkville, Victoria, Australia

4 Department of Clinical Neuroscience, Karolinska Institutet, Stockholm, Sweden

5 Center for Psychiatry Research, Stockholm City Council, Stockholm, Sweden

\section{Introduction}

Antipsychotics are the first-line treatment of schizophrenia [1, 2]. Antipsychotics affect especially positive symptoms, whereas for negative symptoms and cognitive impairment, they are less effective [3]. Antidepressant (AD) or mood stabilizer (MS) use as adjuvants to antipsychotics has been investigated in treatment for symptoms such as depressive and negative symptoms [4] and aggression [5], but they are rarely recommended in clinical guidelines due to lack of high quality evidence of their efficacy $[3,6,7]$. Evidence on benefits in clinical trials is mixed which was represented by a recent study reporting that add-on citalopram was associated with reduced levels of negative symptoms but had no impact on depressive symptoms [8]. In a recent observational study, antidepressant use was associated with lowered risk of psychiatric hospitalization and emergency department visits, whereas mood stabilizers had no impact on these outcomes [9]. In that study, mood stabilizer use was associated with somewhat 
increased risk of mortality, but antidepressant use was not. On the other hand, a previous observational study found cumulative antidepressant exposure to be associated with lower mortality risk compared with no antidepressant use in patients with schizophrenia [10].

The prevalence of AD and MS use in persons with schizophrenia has been previously studied. In United States, Chakos et al. found that $31 \%$ persons with schizophrenia received AD medication, whereas $3 \%$ used lithium and $12 \%$ other mood stabilizer [11]. A study conducted among US Department of Veteran Affairs (VA) healthcare patients reported annual prevalence of $\mathrm{AD}$ use as $37.4 \%$ [12]. A more recent US study reported prevalence as high as $40.6 \% \mathrm{AD}$ use and $32.4 \% \mathrm{MS}$ use as adjunctive treatment with antipsychotics [13]. Similarly high prevalence of AD use was found in persons with schizophrenia in Sweden, namely, 38.8\% [10]. Karagianis and colleagues reported adjunctive use of AD and MS in different continents, and the prevalence of $\mathrm{AD}$ use varied regionally from $15.2 \%$ to $24.1 \%$, and MS use varied from $8.7 \%$ to $19.9 \%$ [14].

There is limited amount of studies concerning antidepressants and mood stabilizers as adjunctive pharmacotherapy for first-episode schizophrenia, and no studies assessing initiation of antidepressant or mood stabilizer use after the diagnoses. The objectives of our study were to investigate antidepressant and mood stabilizer use and factors associated with their initiation in first-episode schizophrenia.

\section{Methods}

\section{Study population}

The source population included all persons who received inpatient care due to schizophrenia from 1972 to 2014 in Finland (ICD-10 diagnoses F20 and F25, ICD-9 and ICD-8 diagnoses 295). This information was obtained from the Hospital Discharge register maintained by National Institute of Health and Welfare. For this study, 8342 persons with a first inpatient diagnoses of schizophrenia, without antipsychotic use during preceding year (short as first-episode schizophrenia) during 1996-2014 were included (mean age 40.6, SD $18.3,56.3 \%$ males), and they formed the study population. More information on this cohort was added from several registers: drug purchase data (1995-2017) was obtained from the National Prescription register maintained by the Social Insurance Institution, all hospital care periods from Hospital Discharge register (1972-2017) and causes of death (19722017) from the National Death register.

\section{Exposure}

Drug purchase data included all reimbursed prescription drug purchases in community pharmacies in Finland and were categorized according to Anatomic Therapeutic Chemical (ATC) classification [15], and by mechanism of action. In this study, the focus was on the use of antidepressants (N06A) and mood stabilizers. Studied antidepressant groups were nonselective monoamine reuptake inhibitors (N06AA), selective serotonin reuptake inhibitors (SSRIs, N06AB), monoamine oxidase A inhibitors (N06AG), and other antidepressants (N06AX). Within other antidepressants, mirtazapine (N06AX11) and serotonin-norepinephrine reuptake inhibitors (SNRIs) were also examined separately. SNRI group included venlafaxine (N06AX16), milnacipran (N06AX17) and duloxetine (N06AX21). Mood stabilizers were defined as carbamazepine (N03AF01), valproic acid (N03AG01) and lamotrigine (N03AX09). Lithium (N05AN01) was included in mood stabilizers.

The register-based drug purchase data does not provide information on the duration of drug use. To investigate the duration, we used the PRE2DUP method, developed by our research group [16]. PRE2DUP estimates drug use periods based on the sliding average of daily doses, purchased amount, and parameters assigned for drug packages which control the joining of purchases. In addition to these, PRE2DUP considers changes of doses, possible inpatient care (wherein drug use is not recorded on the registers) and stockpiling of drugs. PRE2DUP and the validity of this method are described in detail in previous studies [16-18].

\section{Study inclusion criteria}

The inclusion criteria for this study were that the person was diagnosed with schizophrenia in 1996 or after and did not use antipsychotics within a year before the first diagnosis. Prevalence of AD and MS use was assessed within this group $(N=8342)$. For identification of new antidepressant and mood stabilizer users, persons who had ongoing AD and/or MS use at the index date (discharge from the first schizophreniarelated hospitalization) were excluded $(N=675)$ (Supplementary Fig. 1). The final cohort consisted of 7667 persons, who were followed up for $\mathrm{AD}$ and MS initiation for 3 years after the index date.

\section{Outcomes}

The main outcome was initiation of AD or MS use. We also described initiations of AD and MS subgroups by ATC classification and/or by mechanism of action.

\section{Covariates}

Factors associated with the initiation of AD or MS were separately investigated for these two groups. These factors included age, gender, previous suicidal behaviour, substance abuse and the number of previous hospitalizations due to 
psychoses. In addition, comorbid conditions including cardiovascular diseases (CV-diseases), cancer, diabetes, asthma, post-traumatic stress disorder (PTSD) and lipidemias were assessed. We also assessed use of analgesics, anticholinergic anti-Parkinson drugs (for extrapyramidal symptoms of antipsychotics), benzodiazepines and benzodiazepine-related drugs (z-drugs). Detailed definitions of comorbidities are presented in Supplementary Table 1.

\section{Statistical analysis}

Prevalence of AD and MS use, alone or in combination, was assessed as point prevalence every 6 months, from 3 years before and until 3 years after the index date. For initiations of $\mathrm{AD}$ and MS use after the index date, the follow-up ended 3 years after index date, death, or 31st of December 2017, whichever occurred first. Kaplan-Meier analyses were performed to investigate time to the initiation of adjunctive pharmacotherapy. The association between covariates and AD or MS initiation was investigated with Cox proportional hazard models. Associations were reported as unadjusted and adjusted Hazard Ratios (HRs) with $95 \%$ confidence intervals (CIs). Data analyses were performed with SAS for Windows, version 9.4 (SAS Institute Inc., Cary, NC, USA).

\section{Ethics of the study}

The data for this study was collected and combined from registers utilizing personal identification numbers, and no contact was made with the participants of the study. Permissions were granted by pertinent institutional authorities at the Finnish National Institute for Health and Welfare (permission THL/1466/6.02.00/2013), The Social Insurance Institution of Finland (34/522/2013), and Statistics Finland (TK53-305-13). Before submission to the researchers, the data was de-identified, and no informed consent from the participants was required according the Finnish legislation.

\section{Results}

The mean age of the study population was 40.2 years (SD 18.2 ) at the first hospitalization, and $56.8 \%$ were males. Within 3 years of follow-up, $18.3 \%$ had one psychiatric readmission and $28.9 \%$ had more than one, whereas $52.9 \%$ was not readmitted. Prevalence of AD (6.4-8.4\%), MS (1.3-1.7\%) and their concomitant use $(0.6-0.7 \%)$ remained on a constant level from 3 years before until the first schizophrenia diagnoses (Fig. 1). After diagnoses, prevalence of AD and MS use increased and stabilized at a higher level within 1-1.5 years. Three years after the diagnoses, $19.1 \%$ used AD, $6.8 \% \mathrm{MS}$ and $2.7 \%$ used both.
Within 3 years of follow-up, 2713 persons (35.4\%) initiated AD use and 1084 persons (14.1\%) initiated MS use (Fig. 2). The most frequently initiated subgroup of antidepressants was SSRIs (26.3\%), and valproic acid was the most often initiated mood stabilizer $(8.5 \%)$. The mean time to AD initiation was 2.15 years (95\% CI 2.13-2.18) and 2.66 years (95\% CI 2.64-2.68) to MS initiation (Supplementary Fig. 2).

Both antidepressant and mood stabilizer initiators were younger than those who did not initiate these drugs (Table 1). Males initiated MS use more often than females (53.8\% of initiations, $p=0.0289$ ). Among AD initiators, benzodiazepine and $\mathrm{z}$-drug use was more common than among non-initiators, whereas MS initiators used more frequently antidepressants, and benzodiazepines than non-initiators. Suicidal behaviour was more common in both AD and MS initiators, and substance abuse was more common among MS initiators than non-initiators. Considering comorbidities, $\mathrm{CV}$ diseases were more common in those who did not initiate MS or AD use compared to initiators. We also examined ten most commonly used antipsychotics. Among both AD and MS initiators, the most used antipsychotic was olanzapine, followed by risperidone and clozapine except for MS initiators, where clozapine was more commonly used than risperidone.

Female gender and younger age were associated with an increased risk of initiating AD (Table 2). Use of benzodiazepines (aHR 1.78, 95\% CI 1.58-2.01) and z-drugs (aHR 1.28, 95\% CI 1.07-1.54) were associated with AD initiation. Higher number of previous psychoses requiring inpatient care was associated with a reduced risk of initiating antidepressant (one previous psychosis: aHR 0.82, 95\% CI 0.74-0.90, two or more psychoses: aHR $0.71,95 \%$ CI $0.64-0.79$ ) compared to those who had no previous psychoses.

As with antidepressants, female gender and younger age were associated with increased risk of MS initiation (Table 2). Use of antidepressants (aHR 1.22, 95\% CI 1.01-1.48), benzodiazepines (aHR 1.37, 95\% CI 1.12-1.68) and analgesics (aHR 1.39, 95\% CI 1.13-1.72) was also associated with MS initiation. Previous suicidality was also associated with MS initiation (HR 1.30, 95\% CI 1.03-1.65). Considering the number of previous hospitalizations due to psychoses, those who had one or several psychoses were at higher risk of MS initiation compared to those who did not have previous psychosis (aHR 1.22, 95\% CI 1.05-1.42 and 1.22, 95\% CI 1.04-1.42, respectively).

\section{Discussion}

Our study showed that slightly more than one third of persons with first-episode schizophrenia initiated adjunct AD and approximately $15 \%$ initiated MS medication within 3 years of follow-up. Factors associated with both AD and MS initiation were younger age, female gender and use of benzodiazepines. 
Fig. 1 Point prevalence of antidepressant (AD) only, mood stabilizer (MS) only and their concomitant use (AD+MS) from 3 years before and until 3 years after the first schizophrenia diagnoses (time point zero)
25.0

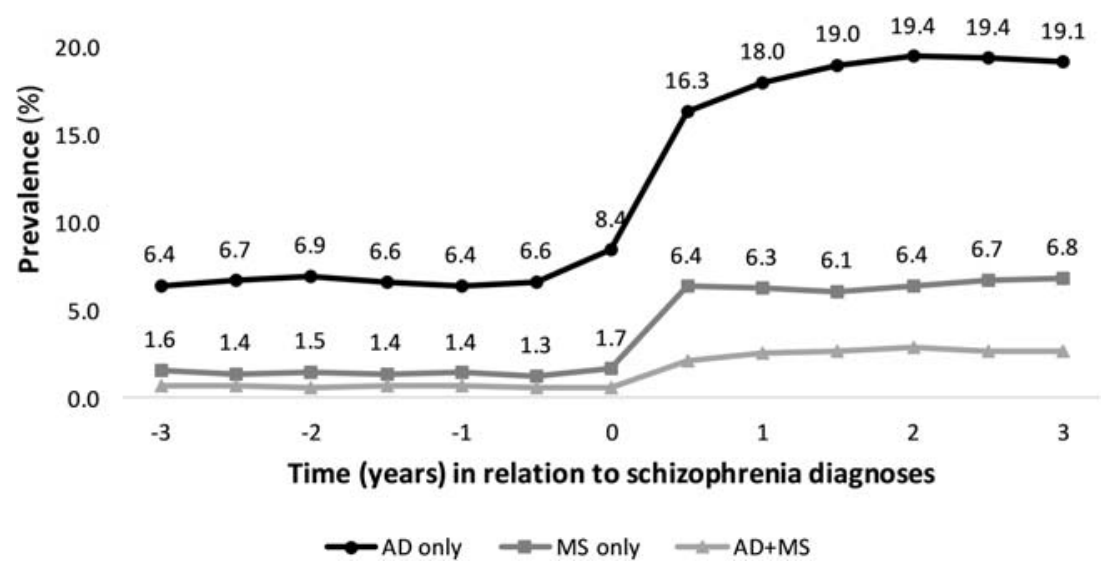

The number of previous hospital-treated psychosis was associated with decreased risk of $\mathrm{AD}$ and increased risk of MS initiation.

According to the best of our knowledge, no previous study has assessed $\mathrm{AD}$ and MS initiations among persons with firstepisode schizophrenia. However, prevalence of AD and MS use reported in previous studies has been somewhat similar $[10,11]$. Olfson and colleagues reported slightly higher AD use and considerably higher MS use [13]. On the other hand, a study considering different continents reported clearly lower prevalence of $\mathrm{AD}$ use throughout the study but showed large regional differences in AD and MS use [14].

We found that female gender and younger age were associated with initiation of adjunctive medication. A previous study found that mood stabilizer use was associated with younger age, aggression and positive symptoms [19]. It is possible that mood stabilizers in our study were initiated for agitation and aggressive behaviour as there is some evidence on effectiveness of mood stabilizers for these symptoms [20]. Antidepressant initiations might reflect prevalence of negative and depressive symptoms, even though evidence of their effectiveness for these symptoms is controversial [4, 6]. More common $\mathrm{AD}$ initiation in women is likely related to the fact that women are more likely to present depressive symptoms than men $[21,22]$. Both AD and MS initiation was associated with benzodiazepine use. Benzodiazepine use may be a marker of anxiety symptoms but their use is controversial and often avoided because benzodiazepine use is associated with risk of dependence, tolerance and withdrawal effects [23]. Thus, AD and MS initiation may be an attempt to treat anxiety symptoms instead of benzodiazepines.

We also found that higher number of previous psychoses was associated with MS initiation, but an inverse association was found for AD initiation. This may be explained by use of MS (such as lithium) to control aggressive behaviour [24] and florid positive symptoms seen especially in schizoaffective disorder, resulting into recurrent hospitalizations. Patients with depressive and negative symptoms may be less frequently hospitalized, and they may receive more often antidepressive add-on treatment.

Persons initiating antipsychotic medication were aged roughly 39 years. This mean age is relatively high but in line with a previous study on first-episode schizophrenia cohort in Sweden [25]. According to a previous study,
Fig. 2 Initiations of mood stabilizer (MS) and antidepressant (AD) subgroups within 3 years after antipsychotic initiation. TCA tricyclic antidepressant, SSRI selective serotonin reuptake inhibitor, SNRI serotoninnorepinephrine reuptake inhibitor. Percentages of subgroups may not add up to total MS or AD category percentage because some persons initiated with multiple drugs or drug categories

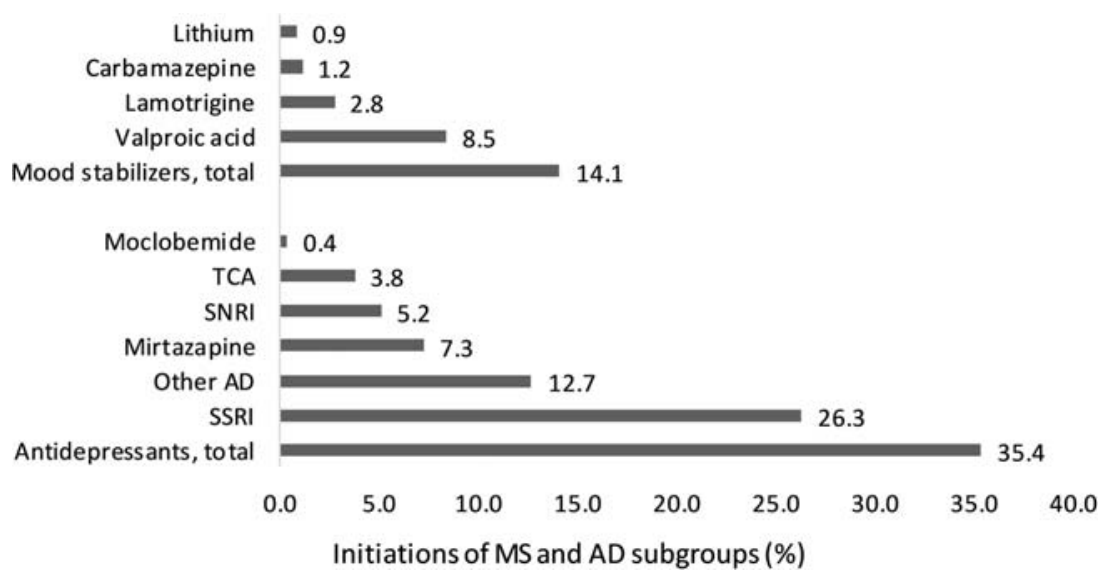


Table 1 Characteristics of antidepressant and mood stabilizer initiators and non-initiators

\begin{tabular}{|c|c|c|c|c|c|c|}
\hline & \multicolumn{3}{|c|}{ Antidepressant \% (N) } & \multicolumn{3}{|c|}{ Mood stabilizer \% (N) } \\
\hline & $\begin{array}{l}\text { Initiator } \\
(N=2713)\end{array}$ & $\begin{array}{l}\text { Non- } \\
\text { initiator } \\
(N=4954)\end{array}$ & $P$ value & $\begin{array}{l}\text { Initiator } \\
(N=1084)\end{array}$ & $\begin{array}{l}\text { Non- } \\
\text { initiator } \\
(N=6583)\end{array}$ & $P$ value \\
\hline Age categories & & & $<0.0001$ & & & $<0.0001$ \\
\hline$\leq 20$ & $7.7(210)$ & $5.3(261)$ & & $9.4(102)$ & $5.6(369)$ & \\
\hline $21-30$ & $35.5(963)$ & $26.8(1328)$ & & $34.7(376)$ & $29.1(1915)$ & \\
\hline $31-40$ & $21.3(578)$ & $19.2(949)$ & & $23.2(251)$ & $19.4(1276)$ & \\
\hline $41-50$ & $15.3(416)$ & $15.6(773)$ & & $16.0(173)$ & $15.4(1016)$ & \\
\hline $51-60$ & $9.7(263)$ & $13.0(643)$ & & $9.7(105)$ & $12.2(801)$ & \\
\hline$>60$ & $10.4(283)$ & $20.2(1000)$ & & $7.1(77)$ & $18.3(1206)$ & \\
\hline Female gender & $44.1(1195)$ & $42.7(2115)$ & 0.2523 & $46.2(501)$ & $42.7(2809)$ & 0.0289 \\
\hline Antidepressant & & & & $12.4(134)$ & $8.7(573)$ & 0.0001 \\
\hline Mood stabilizer & $4.0(108)$ & $2.7(135)$ & 0.0027 & & & \\
\hline Anticholinergic anti-Parkinson drugs & $1.644)$ & $1.1(55)$ & 0.0578 & $1.4(15)$ & $1.3(84)$ & 0.7709 \\
\hline Benzodiazepines & $12.7(345)$ & $6.6(325)$ & $<0.0001$ & $11.4(124)$ & $8.3(546)$ & 0.0007 \\
\hline Z-drugs & $4.9(132)$ & $3.5(171)$ & 0.0024 & $4.2(46)$ & $3.9(257)$ & 0.5949 \\
\hline Analgesics & $9.2(250)$ & $8.2(404)$ & 0.1121 & $9.8(106)$ & $8.3(548)$ & 0.1122 \\
\hline Substance abuse & $13.8(375)$ & $13.5(668)$ & 0.6795 & $16.2(176)$ & $13.2(867)$ & 0.0064 \\
\hline Suicidality & $6.2(169)$ & $4.7(231)$ & 0.0032 & $7.6(82)$ & $4.8(318)$ & 0.0002 \\
\hline CV-diseases & $9.6(259)$ & $13.4(663)$ & $<0.0001$ & $7.7(83)$ & 12.7 (839) & $<0.0001$ \\
\hline Cancer & $1.6(42)$ & $2.4(118)$ & 0.0146 & $0.9(10)$ & $2.3(150)$ & 0.0038 \\
\hline Diabetes & $3.0(82)$ & $4.5(224)$ & 0.0013 & $2.8(30)$ & $4.2(276)$ & 0.0263 \\
\hline Asthma & $3.5(96)$ & $3.1(155)$ & 0.3350 & $3.7(40)$ & $3.2(211)$ & 0.4059 \\
\hline PTSD & $0.4(11)$ & $0.3(15)$ & 0.4596 & $0.5(5)$ & $0.3(21)$ & 0.4554 \\
\hline Lipoprotein disorders & $2.7(74)$ & $3.4(168)$ & 0.1120 & $1.9(21)$ & $3.4(221)$ & 0.0132 \\
\hline Previous psychoses & & & $<0.0001$ & & & 0.0051 \\
\hline None & $66.2(1796)$ & $59.1(2930)$ & & $57.2(620)$ & $62.4(4109)$ & \\
\hline 1 & $18.7(506)$ & $20.8(1032)$ & & $22.3(242)$ & $19.7(1296)$ & \\
\hline$\geq 2$ & $15.2(411)$ & $20.0(992)$ & & $20.5(222)$ & $17.9(1181)$ & \\
\hline \multicolumn{7}{|c|}{ Ten most commonly used antipsychotics at the time of AD or MS initiation } \\
\hline Olanzapine & $19.0(515)$ & & & $18.0(195)$ & & \\
\hline Risperidone & $13.3(360)$ & & & $10.6(115)$ & & \\
\hline Clozapine & $11.6(316)$ & & & $14.8(160)$ & & \\
\hline Quetiapine & $4.8(131)$ & & & $5.6(61)$ & & \\
\hline Perphenazine & $2.8(77)$ & & & $2.1(23)$ & & \\
\hline Aripiprazole & $1.9(51)$ & & & $1.3(14)$ & & \\
\hline Risperidone LAI & $1.8(49)$ & & & $1.5(16)$ & & \\
\hline Perphenazine LAI & $1.2(33)$ & & & $0.7(8)$ & & \\
\hline Haloperidol & $1.0(27)$ & & & $1.1(12)$ & & \\
\hline Zuclopenthixol LAI & $1.0(27)$ & & & $1.2(13)$ & & \\
\hline Other AP & $5.8(157)$ & & & $7.0(76)$ & & \\
\hline AP polytherapy & $19.2(521)$ & & & $23.1(250)$ & & \\
\hline No AP & $16.5(449)$ & & & $13.0(141)$ & & \\
\hline
\end{tabular}

$C V$-diseases cardiovascular diseases, PTSD post-traumatic stress disorder, Lipoprotein disorders: Disorders of lipoprotein metabolism and other lipidemias, $L A I$ long-acting injection, AP polytherapy: two or more antipsychotics in use simultaneously

Finnish inpatient care diagnoses of schizophrenia have high validity (no false positive cases), but the register data may lack some persons fulfilling the diagnostic criteria for schizophrenia [26]. This likely reflects diagnostic delay in setting the final 
Table 2 Factors associated with antidepressant and mood stabilizer initiation

\begin{tabular}{|c|c|c|c|c|c|c|c|c|c|c|c|}
\hline \multicolumn{6}{|c|}{ Antidepressants } & \multicolumn{6}{|c|}{ Mood stabilizers } \\
\hline \multicolumn{3}{|c|}{ Unadjusted } & \multicolumn{3}{|c|}{ Adjusted } & \multicolumn{3}{|c|}{ Unadjusted } & \multicolumn{3}{|c|}{ Adjusted } \\
\hline HR & $\begin{array}{l}\text { Lower } \\
\text { CI }\end{array}$ & $\begin{array}{l}\text { Upper } \\
\text { CI }\end{array}$ & HR & $\begin{array}{l}\text { Lower } \\
\text { CI }\end{array}$ & $\begin{array}{l}\text { Upper } \\
\text { CI }\end{array}$ & HR & $\begin{array}{l}\text { Lower } \\
\text { CI }\end{array}$ & $\begin{array}{l}\text { Upper } \\
\text { CI }\end{array}$ & HR & $\begin{array}{l}\text { Lower } \\
\text { CI }\end{array}$ & $\begin{array}{l}\text { Upper } \\
\text { CI }\end{array}$ \\
\hline
\end{tabular}

\begin{tabular}{|c|c|c|c|c|c|c|c|c|c|c|c|c|}
\hline \multicolumn{13}{|l|}{ Age categories } \\
\hline$\leq 20$ & 2.15 & 1.79 & 2.56 & 2.56 & 2.11 & 3.11 & 3.65 & 2.71 & 4.90 & 4.03 & 2.92 & 5.55 \\
\hline $21-30$ & 2.03 & 1.78 & 2.32 & 2.43 & 2.08 & 2.83 & 2.73 & 2.13 & 3.48 & 2.97 & 2.25 & 3.91 \\
\hline $31-40$ & 1.79 & 1.55 & 2.06 & 2.13 & 1.81 & 2.49 & 2.75 & 2.13 & 3.55 & 2.85 & 2.16 & 3.77 \\
\hline $41-50$ & 1.62 & 1.40 & 1.89 & 1.88 & 1.60 & 2.22 & 2.41 & 1.84 & 3.15 & 2.44 & 1.83 & 3.25 \\
\hline $51-60$ & 1.31 & 1.11 & 1.55 & 1.45 & 1.21 & 1.72 & 1.92 & 1.43 & 2.58 & 1.91 & 1.41 & 2.59 \\
\hline \multicolumn{13}{|l|}{$>60$ (reference) } \\
\hline Female gender & 1.06 & 0.98 & 1.14 & 1.19 & 1.10 & 1.29 & 1.15 & 1.02 & 1.30 & 1.33 & 1.17 & 1.51 \\
\hline Mood stabilizers & 1.37 & 1.13 & 1.66 & 1.18 & 0.97 & 1.43 & NA & & & NA & & \\
\hline Antidepressants & NA & & & NA & & & 1.44 & 1.20 & 1.72 & 1.22 & 1.01 & 1.48 \\
\hline $\begin{array}{l}\text { Anticholinergic anti-Parkinson } \\
\text { drugs }\end{array}$ & 1.35 & 1.00 & 1.82 & 1.11 & 0.82 & 1.51 & 1.08 & 0.65 & 1.80 & 0.91 & 0.55 & 1.53 \\
\hline Benzodiazepines & 1.82 & 1.63 & 2.04 & 1.78 & 1.58 & 2.01 & 1.43 & 1.19 & 1.73 & 1.37 & 1.12 & 1.68 \\
\hline Z-drugs & 1.38 & 1.16 & 1.65 & 1.28 & 1.07 & 1.54 & 1.12 & 0.83 & 1.50 & 1.12 & 0.82 & 1.52 \\
\hline Analgesics & 1.16 & 1.02 & 1.32 & 1.15 & 1.00 & 1.32 & 1.22 & 1.00 & 1.49 & 1.39 & 1.13 & 1.72 \\
\hline Substance abuse & 1.03 & 0.92 & 1.15 & 1.00 & 0.90 & 1.13 & 1.25 & 1.06 & 1.47 & 1.16 & 0.98 & 1.38 \\
\hline Suicidality & 1.27 & 1.09 & 1.48 & 1.17 & 0.99 & 1.37 & 1.55 & 1.24 & 1.94 & 1.30 & 1.03 & 1.65 \\
\hline CV-diseases & 0.78 & 0.69 & 0.89 & 1.01 & 0.87 & 1.16 & 0.62 & 0.50 & 0.78 & 0.88 & 0.69 & 1.13 \\
\hline Cancer & 0.77 & 0.57 & 1.05 & 1.09 & 0.80 & 1.49 & 0.45 & 0.24 & 0.84 & 0.69 & 0.37 & 1.30 \\
\hline Diabetes & 0.76 & 0.61 & 0.94 & 0.91 & 0.72 & 1.16 & 0.70 & 0.49 & 1.01 & 1.00 & 0.68 & 1.47 \\
\hline Asthma & 1.10 & 0.89 & 1.34 & 1.11 & 0.90 & 1.36 & 1.17 & 0.85 & 1.60 & 1.23 & 0.89 & 1.68 \\
\hline PTSD & 1.15 & 0.64 & 2.08 & 0.89 & 0.49 & 1.62 & 1.40 & 0.58 & 3.36 & 0.99 & 0.41 & 2.39 \\
\hline Lipoprotein disorders & 0.86 & 0.69 & 1.09 & 1.21 & 0.94 & 1.56 & 0.61 & 0.40 & 0.94 & 1.02 & 0.64 & 1.62 \\
\hline \multicolumn{13}{|l|}{ Previous psychoses } \\
\hline \multicolumn{13}{|l|}{0 (reference) } \\
\hline 1 & 0.83 & 0.75 & 0.91 & 0.82 & 0.74 & 0.90 & 1.22 & 1.06 & 1.42 & 1.22 & 1.05 & 1.42 \\
\hline$\geq 2$ & 0.71 & 0.64 & 0.79 & 0.71 & 0.64 & 0.79 & 1.22 & 1.05 & 1.42 & 1.22 & 1.04 & 1.42 \\
\hline
\end{tabular}

CV-diseases cardiovascular diseases, PTSD post-traumatic stress disorder, Lipoprotein disorders: Disorders of lipoprotein metabolism and other lipidemias

diagnoses, which is also supported by the fact that a large proportion of persons had used antipsychotics before their first diagnoses [27].

Our study has certain strengths and limitations. Finnish nationwide registers provide reliable information on schizophrenia, and comprehensive data of dispensed medications. Register-based studies usually have also limitations. The utilized registers, for example, do not offer data of indications of use or severity of symptoms. In addition, medication use during inpatient care is not recorded in the registers, and thus we lacked this information. The utilized registers include only persons diagnosed in inpatient care with schizophrenia and lack data on schizophrenia patients diagnosed only in outpatient care. However, persons with schizophrenia tend to be admitted into inpatient care at re-emergence of psychosis, and for this reason, this has only limited impact on the generalizability of our study. We lacked data on primary non-adherence, i.e., prescribed drugs that are never dispensed, and doses.

In conclusion, persons with first-episode schizophrenia relatively often use adjunctive AD and/or MS medication. As there is limited evidence of their effectiveness, more studies are needed to investigate the benefits and risks of these adjunctive medications.

Acknowledgements Open access funding provided by University of Eastern Finland (UEF) including Kuopio University Hospital.

Author contributions Conceptualization: Arto Puranen, Heidi Taipale. Methodology: Arto Puranen, Heidi Taipale, Marjaana Koponen, Antti Tanskanen. Formal analysis and investigation: Arto Puranen, Heidi 
Taipale. Writing - original draft preparation: Arto Puranen. Writing review and editing: All authors. Funding acquisition: Heidi Taipale, Jari Tiihonen. Critical revision of the manuscript for important intellectual content: All authors.

Funding This study was funded by the Finnish Ministry of Social Affairs and Health through the developmental fund for Niuvanniemi Hospital. HT and AP were funded by Academy of Finland (grants 315969, 320107). The funders of the study had no role in study design, data collection, data analysis, data interpretation, review or approval of the manuscript, or in the decision to submit the manuscript for publication.

\section{Compliance with ethical standards}

Conflict of interest Jari Tiihonen, Heidi Taipale and Antti Tanskanen have participated in research projects funded by grants from JanssenCilag and Eli Lilly to their employing institution. Jari Tiihonen reports personal fees from the Finnish Medicines Agency (Fimea), European Medicines Agency (EMA), Eli Lilly, Janssen-Cilag, Lundbeck, and Otsuka; is a member of advisory board for Lundbeck, and has received grants from the Stanley Foundation and Sigrid Jusélius Foundation. The other authors report no conflict of interest.

Open Access This article is licensed under a Creative Commons Attribution 4.0 International License, which permits use, sharing, adaptation, distribution and reproduction in any medium or format, as long as you give appropriate credit to the original author(s) and the source, provide a link to the Creative Commons licence, and indicate if changes were made. The images or other third party material in this article are included in the article's Creative Commons licence, unless indicated otherwise in a credit line to the material. If material is not included in the article's Creative Commons licence and your intended use is not permitted by statutory regulation or exceeds the permitted use, you will need to obtain permission directly from the copyright holder. To view a copy of this licence, visit http://creativecommons.org/licenses/by/4.0/.

\section{References}

1. Leucht S, Cipriani A, Spineli L, Mavridis D, Orey D, Richter F, Samara M, Barbui C, Engel RR, Geddes JR, Kissling W, Stapf MP, Lässig B, Salanti G, Davis JM (2013) Comparative efficacy and tolerability of 15 antipsychotic drugs in schizophrenia: a multipletreatments meta-analysis. Lancet 382:951-962. https://doi.org/10. 1016/S0140-6736(13)60733-3

2. (2015) Schizophrenia: Current care guideline. www.kaypahoito.fi. Accessed 5 Jul 2019

3. Buchanan RW, Kreyenbuhl J, Kelly DL, Noel JM, Boggs DL, Fischer BA, Himelhoch S, Fang B, Peterson E, Aquino PR, Keller W, Schizophrenia Patient Outcomes Research Team (PORT) (2010) The 2009 schizophrenia PORT psychopharmacological treatment recommendations and summary statements. Schizophr Bull 36:71-93. https://doi.org/10.1093/schbul/sbp116

4. Helfer B, Samara MT, Huhn M et al (2016) Efficacy and safety of antidepressants added to antipsychotics for schizophrenia: a systematic review and meta-analysis. Am J Psychiatry 173:876-886. https://doi.org/10.1176/appi.ajp.2016.15081035

5. Wang Y, Xia J, Helfer B, Li C, Leucht S (2016) Valproate for schizophrenia (review). Cochrane Database Syst Rev. https://doi. org/10.1002/14651858.CD004028.pub4

6. Galling B, Vernon JA, Pagsberg AK, Wadhwa A, Grudnikoff E, Seidman AJ, Tsoy-Podosenin M, Poyurovsky M, Kane JM, Correll
CU (2018) Efficacy and safety of antidepressant augmentation of continued antipsychotic treatment in patients with schizophrenia. Acta Psychiatr Scand 137:187-205. https://doi.org/10.1111/acps. 12854

7. Zink M, Englisch S, Meyer-Lindenberg A (2010) Polypharmacy in schizophrenia. Curr Opin Psychiatry 23:103-111. https://doi.org/ 10.1097/YCO.0b013e3283366427

8. Goff DC, Freudenreich O, Cather C, Holt D, Bello I, Diminich E, Tang Y, Ardekani BA, Worthington M, Zeng B, Wu R, Fan X, Li C, Troxel A, Wang J, Zhao J (2019) Citalopram in first episode schizophrenia: the DECIFER trial. Schizophr Res 208:331-337. https:// doi.org/10.1016/j.schres.2019.01.028

9. Stroup TS, Gerhard T, Crystal S, Huang C, Tan Z, Wall MM, Mathai C, Olfson M (2019) Comparative effectiveness of adjunctive psychotropic medications in patients with schizophrenia. JAMA Psychiatry 76:508-515. https://doi.org/10.1001/ jamapsychiatry.2018.4489

10. Tiihonen J, Mittendorfer-Rutz E, Torniainen M et al (2016) Mortality and cumulative exposure to antipsychotics, antidepressants, and benzodiazepines in patients with schizophrenia: an observational follow-up study. Am J Psychiatry 173:600-606. https:// doi.org/10.1176/appi.ajp.2015.15050618

11. Chakos MH, Glick ID, Miller AL, Hamner MB, Miller DD, Patel JK, Tapp A, Keefe RS, Rosenheck RA (2006) Baseline use of concomitant psychotropic medications to treat schizophrenia in the CATIE trial. Psychiatr Serv 57:1094-1101. https://doi.org/10. 1176/ps.2006.57.8.1094

12. Himelhoch S, Slade E, Kreyenbuhl J et al (2012) Antidepressant prescribing patterns among VA patients with schizophrenia. Schizophr Res 136:32-35. https://doi.org/10.1016/j.schres.2012. 01.008

13. Olfson M, Marcus SC, Wan GJ (2009) Treatment patterns for schizoaffective disorder and schizophrenia among Medicaid patients. Psychiatr Serv 60:210-216. https://doi.org/10.1176/ps. 2009.60.2.210

14. Karagianis J, Novick D, Pecenak J, Haro JM, Dossenbach M, Treuer T, Montgomery W, Walton R, Lowry AJ (2009) Worldwide-schizophrenia outpatient health outcomes (W-SOHO): baseline characteristics of pan-regional observational data from more than 17,000 patients. Int J Clin Pract 63:1578-1588. https:// doi.org/10.1111/j.1742-1241.2009.02191.x

15. WHO (2018) ATC-DDD: structure and principles. Methodology, WHO Collaborating Centre for Drug Statistic. https://www. whocc.no/atc/structure and principles/. Accessed 29 May 2019

16. Tanskanen A, Taipale $\bar{H}$, Koponen M, Tolppanen AM, Hartikainen S, Ahonen R, Tiihonen J (2015) From prescription drug purchases to drug use periods - a second generation method (PRE2DUP). BMC Med Inform Decis Mak 15:1-13. https://doi.org/10.1186/ s12911-015-0140-Z

17. Forsman J, Taipale H, Masterman T et al (2018) Comparison of dispensed medications and forensic-toxicological findings to assess pharmacotherapy in the Swedish population 2006 to 2013. Pharmacoepidemiol Drug Saf 27:1112-1122. https://doi.org/10. $1002 /$ pds.4426

18. Taipale H, Tanskanen A, Koponen M, Tolppanen AM, Tiihonen J, Hartikainen S (2016) Agreement between PRE2DUP register data modeling method and comprehensive drug use interview among older persons. Clin Epidemiol 8:363-371. https://doi.org/10.2147/ CLEP.S116160

19. Sim K, Yong KH, Chan YH, Tor PC, Xiang YT, Wang CY, Lee EH, Fujii S, Yang SY, Chong MY, Ungvari GS, Si T, He YL, Chung EK, Chee KY, Trivedi J, Udomratn P, Shinfuku N, Kua EH, Tan CH, Sartorius N, Baldessarini RJ (2011) Adjunctive mood stabilizer treatment for hospitalized schizophrenia patients: Asia psychotropic prescription study (2001-2008). Int J Neuropsychopharmacol 14: 1157-1164. https://doi.org/10.1017/S1461145711000563 
20. Huband N, Ferriter M, Nathan R, Jones H (2010) Antiepileptics for aggression and associated impulsivity (review). Cochrane Database Syst Rev. https://doi.org/10.1002/14651858.CD003499.pub3

21. Morgan VA, Castle DJ, Jablensky AV (2008) Do women express and experience psychosis differently from men? Epidemiological evidence from the Australian National Study of low prevalence (psychotic) disorders. Aust N Z J Psychiatry 42:74-82. https://doi. org/10.1080/00048670701732699

22. Cotton SM, Lambert M, Schimmelmann BG et al (2009) Gender differences in premorbid, entry, treatment, and outcome characteristics in a treated epidemiological sample of 661 patients with first episode psychosis. Schizophr Res 114:17-24. https://doi.org/10. 1016/j.schres.2009.07.002

23. Dell'osso B, Lader M (2013) Do benzodiazepines still deserve a major role in the treatment of psychiatric disorders? A critical reappraisal. Eur Psychiatry 28:7-20. https://doi.org/10.1016/j.eurpsy. 2011.11.003

24. Correll CU, Yu X, Xiang Y, Kane JM, Masand P (2017) Biological treatment of acute agitation or aggression with schizophrenia or bipolar disorder in the inpatient setting. Ann Clin Psychiatry 29: 92-107
25. Tiihonen J, Mittendorfer-Rutz E, Majak M, Mehtälä J, Hoti F, Jedenius E, Enkusson D, Leval A, Sermon J, Tanskanen A, Taipale H (2017) Real-world effectiveness of antipsychotic treatments in a nationwide cohort of 29823 patients with schizophrenia. JAMA Psychiatry 74:686-693. https://doi.org/10.1001/ jamapsychiatry.2017.1322

26. Isohanni M, Mäkikyrö T, Moring J, Räsänen P, Hakko H, Partanen U, Koiranen M, Jones P (1997) A comparison of clinical and research DSM-III-R diagnoses of schizophrenia in a Finnish national birth cohort. Soc Psychiatry Psychiatr Epidemiol 32:303-308. https://doi.org/10.1007/BF00789044

27. Tiihonen J, Tanskanen A, Taipale H (2018) 20-year Nationwide follow-up study on discontinuation of antipsychotic treatment in first-episode schizophrenia. Am J Psychiatry 175:765-773. https://doi.org/10.1176/appi.ajp.2018.17091001

Publisher's note Springer Nature remains neutral with regard to jurisdictional claims in published maps and institutional affiliations. 